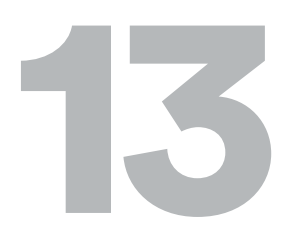

\title{
Arqueología subacuática en México y Latinoamérica
}

Roberto Esteban Junco Sánchez

Subdirector de Arqueología Subacuática, INAH (México)

La arqueología subacuática en México y Latinoamérica atraviesa un gran momento, ya que la disciplina ha cobrado una presencia permanente entre investigadores de casi todos los países y se practica cada vez más y con mejores estándares de calidad. Existe una conciencia y un auténtico interés por descubrir y preservar el patrimonio cultural subacuático. Habría que decir que ya transitamos por la época en que el patrimonio se encontraba a la merced de algunos exploradores, cazadores de tesoros y entusiastas con buenas intenciones. Tampoco nos encontramos en ese paso natural, en que las instituciones nacionales comenzaron a incorporar conceptos y leyes de protección y acciones para proteger los yacimientos arqueológicos, así como regular la investigación con algunos de los primeros proyectos formales. Podemos decir que hoy en América Latina la disciplina se encuentra en auge y un gran número de especialistas la practican, se publican trabajos y se presentan resultados. Esto no es decir que estamos en el mejor de los mundos posibles, sin embargo, las bases para un desarrollo sólido y sostenible están presentes en un buen número de países. Muchas son las razones que han permitido llegar al punto en que nos encontramos. Entre estas, la Convención de la UNESCO para el Patrimonio Cultural Subacuático de 2002 ha dado fuerza a la disciplina, si bien no todos los países son signatarios aún.
A través de la Convención, se han ido estableciendo guiños y ejemplos que han sido abrazados por todo el que ha querido adentrarse en este tema. Además, las iniciativas de la UNESCO para educar han sido importantes, tanto en cursos como en publicaciones, como el Manual para actividades dirigidas al Patrimonio Cultural Subacuático. Directrices para el anexo de la Convención de la UNESCO de 2001 (MAARLEVELD; GUÉRIN; EGGER, 2013). Esta convención ha favorecido, en el caso mexicano, el fortalecimiento de leyes que permiten defender y estudiar el patrimonio. Entre otras influencias positivas para el desarrollo de la disciplina, se han dado cursos en diferentes países para formar futuros investigadores. Tal es el caso de los cursos de la Nautical Archaeological Society (NAS), que han dado bases a muchos investigadores (BOWENS, 2008). También podemos decir que cada día crece el número de egresados de programas de arqueología subacuática en países del primer mundo, formando profesionales que regresan a sus países y traen las metodologías y técnicas más novedosas sin importar el nivel en que se encuentra la disciplina en ese país. Esto permite decir que, sin importar el desarrollo de cada país, el esfuerzo de cooperación que existe en el gremio capacita y da herramientas para estar al día y realizar los mejores trabajos. Sin embargo, es verdad que el financiamiento es la parte espinosa para los arqueólogos. Aun así, existen líneas y proyectos que con escasos recursos pueden tener resultados importantes. Y aprovecho para mencionar que muchos han sido los investigadores que han logrado becas internacionales para desarrollar proyectos, como son las becas de la National Geographic Society, que han sido un verdadero estímulo para varios de 


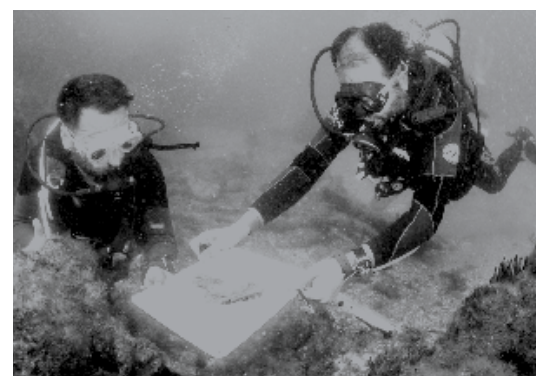

Arqueólogos tomando medidas de un hueso bajo el agua en un pecio de la Baja California. Foto Alfredo Martínez

\author{
"Hay que fortalecer el \\ hábito de la publicación \\ de resultados, lo cual es \\ cada día más sencillo \\ gracias a los medios \\ electrónicos y la variada \\ oferta en publicaciones \\ internacionales"
}

nosotros. Si bien no todos los países han podido avanzar en este sentido, e incluso hay países que han optado por tomar otras vías para gestionar su patrimonio, opuesto a algunos puntos de la Convención, el consenso es que la labor de investigadores por todos los países ha generado trabajos de calidad en esta materia. Esto permite ver un futuro aún más vibrante para la arqueología latinoamericana.

El caso particular de México es interesante. La arqueología subacuática en este país comienza tan temprano como 1891, con la expedición del célebre arqueólogo Francisco del Paso y Troncoso, quien con buzos de escafandra explora las aguas de la Villa Rica, Veracruz, para encontrar vestigios de los barcos hundidos por Hernán Cortés. Otros trabajos se suceden en cenotes de Yucatán, mares y lagos. Sin embargo, en términos de la disciplina como la conocemos en nuestros días, el órgano oficial del Gobierno para estos temas, el INAH, establece en 1980 el área específica, la Dirección de Arqueología Subacuática, la cual es promovida a Subdirección en 1995. En estos 38 años la Subdirección de Arqueología Subacuática ha promovido varias líneas de investigación y proyectos, entre los que destacan el Inventario de recursos culturales sumergidos, con el fin de tener una idea del tamaño del patrimonio nacional bajo el agua. El universo del patrimonio cultural sumergido en México es amplio. No solo contamos con mares, sino que también tenemos sitios prehistóricos en cuevas sumergidas y evidencia prehispánica por todo tipo de cuerpos de agua del interior. Por otra parte, México ha logrado frenar las iniciativas de cazatesoros que han buscado mil maneras de operar en nuestras aguas. Si bien los retos y resultados de la labor pueden ser cuestionables, México ha servido como ejemplo de gestión para los colegas latinoamericanos durante muchos años.
El futuro de la disciplina en Latinoamérica es brillante; nuevas técnicas en el registro de contextos subacuáticos, como es la fotogrametría, permiten hacer más barato y rápido un registro de mayor cantidad. Los desarrollos teóricos permiten hacer trabajos más profundos. Muchos países cuentan con legislación y arqueólogos capacitados, y varios han dejado precedentes importantes en sus investigaciones. Sin embargo, hay que fortalecer el hábito de la publicación de resultados, lo cual es cada día más sencillo gracias a los medios electrónicos y la variada oferta en publicaciones internacionales. En fin, por donde se mire la disciplina va en ascenso y esto solo puede favorecer a nuestro patrimonio que finalmente podemos considerar de todos y del cual somos meros guardianes por un rato.

\section{Bibliografía}

BOWENS, A. (ed.) (2008) Underwater Archaeology: The Nas Guide to Principles and Practice. Malden, MA; Oxford: Blackwell Publishing; Portsmouth, UK: Nautical Archaeology Society, 2008

MAARLEVELD, T. J.; GUÉRIN, U.; EGGER, B. (2013) Manual para actividades dirigidas al Patrimonio Cultural Subacuatico. Directrices para el anexo de la Convención de la UNESCO de 2001. París: UNESCO, 2013 